\title{
Preface for the Original Text
}

It was around three years ago, but I was very confused at the request of writing a book about my work. The theory of semilinear elliptic equations had been advanced extensively, and my contribution was almost nothing. Besides, I am not a good story teller.

However, it has been out! Therefore, I have to excuse myself.

The book is mostly based on the lectures delivered at various places. I need five chapters. Each is provided with an introduction, preliminary material, proofs, and conclusion, and can be read independently, in spite of the fact that all are connected with each other significantly inside. I intended the book to be an invitation to the nonlinear problems. It is not self-contained, nor does it contains all of the celebrated work. But readers are supposed to be acquainted with some of the fundamental ideas.

The equations are quite simple, but have a lot of suggestions. Maybe that is why many people have been attracted to them so much, and the study is still in progress.

In the autumn of 1984, I learned a surprising result of $\mathrm{H}$. Wente concerning the soap bubble. Before, I did not know the way to apply the complex function theory to nonlinear problems. That was the time I began the study such equations.

Throughout these ten years, I have been engaged in a few problems, but most of them had been motivated by the personal experience. Here, I just express my gratitude to H. Ishii, S. Sakaguchi, and Y. Yamada for careful reading of the preliminary version.

Even now, I am not sure that I had been a good writer, but I appreciate Professor N. Kenmochi very much for providing me with this opportunity.

October, 1994

Takashi Suzuki 
